\title{
The footprint of evolutionary processes of learning and selection upon the statistical properties of industrial dynamics
}

\author{
Marcelo C. Pereira ${ }^{* 1}$, Giovanni Dosi ${ }^{\dagger 2}$ and Maria Enrica Virgillito ${ }^{\ddagger 2}$ \\ ${ }^{1}$ Universidade Estadual de Campinas \\ ${ }^{2}$ Scuola Superiore Sant'Anna
}

July 2015

\begin{abstract}
Evolutionary theories of economic change identify the processes of idiosyncratic learning by individual firms and of market selection as the two main drivers of the dynamics of industries. Are such processes able to account for the statistical regularities which industrial structures and dynamics display? In this work we address this question by means of a simple multi-firm model formalizing the mechanisms of learning and selection. As such, despite its simplicity, the model is able to robustly reproduce an ensemble of empirical stylised facts, including ample heterogeneity in productivity distributions, persistent market turbulence and fat-tailed distribution of growth rates.

Teorias evolucionárias da mudança econômica identificam os processos de aprendizado idiossincrático, pelas empresas individuais, e de seleção, no mercado, como os dois principais motores da dinâmica industrial. Seriam esses processos capazes de explicar as regularidades estatísticas que as estruturas industriais e sua dinâmica apresentam? Neste trabalho abordamos essa questão por meio de um modelo multiempresas simples que formaliza os mecanismos de aprendizado e seleção. Apesar de sua simplicidade, o modelo é capaz de reproduzir de modo robusto um conjunto de fatos estilizados empíricos, incluindo a grande heterogeneidade na distribuição das produtividades, a turbulência persistente no mercado e a cauda longa da distribuição das taxas de crescimento.
\end{abstract}

\section{Keywords}

Firm Growth, Heterogeneous Productivities, Fat Tail Distributions, Learning, Market Selection. Crescimento das Firmas, Produtividades Heterogêneas, Distribuições de Cauda Longa, Aprendizado, Seleção de Mercado.

\section{JEL Classification}

C63-L11-L6

\section{ANPEC Area}

Economia Industrial e da Tecnologia

\section{Acknowledgements}

We thank Marco Grazzi, Luigi Marengo, Andrea Roventini and Angelo Secchi for helpful comments and discussions. We gratefully acknowledge the support to one of us (M.C. Pereira) by CNPq, Project 400548/2014-3.

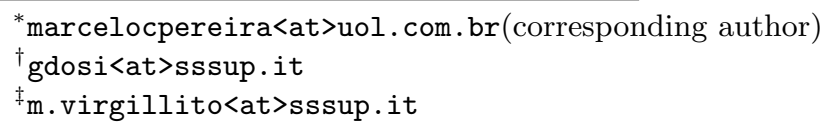




\section{Introduction}

Evolutionary theories of economic change identify the processes of idiosyncratic learning by individual firms and of market selection as the two main drivers of the dynamics of industries. The interplay between these two engines shapes the dynamics of entry-exit and market shares and, collectively, the productivities and size distributions, and the patterns of growth of both variables. Learning (what in the empirical literature is sometimes broadly called the within effect) stands for various processes of idiosyncratic innovation, imitation, and changes in techniques of production. Selection (what is usually denominated the between effect) is the outcome of processes of market interaction where more competitive firms gain market share at the expense of less competitive ones, some firms die, and others enter. The ensuing industrial dynamics presents some remarkable and quite robust statistical properties - "stylized facts" - which tend to hold across industries and countries, levels of aggregation and time periods (for a critical surveys, see Dosi, 2007, Doms and Bartelsman, 2000, and Syverson, 2011).

In particular, such stylized facts include:

- persistent heterogeneity in productivity and all other performance variables;

- persistent market turbulence, due to change in market shares and entry-exit processes;

- skewed size distributions;

- fat-tailed distribution of growth rates;

- scaling of the growth-variance relationship.

Different theoretical perspectives address the interpretation of one or more of such empirical regularities. One stream of analysis, which could go under the heading of equilibrium evolution, tries to interpret size dynamics in term of passive (Jovanovic (1982)) or active learning (Ericson and Pakes (1995)) by technically heterogeneous but "rational" firms. Another stream - from the pioneering work by Ijiri and H. Simon (1977) all the way to Bottazzi and Secchi (2006a) - studies the joint outcome of both learning and selection mechanisms in terms of the ensuing exploitation of new business opportunities.

A third stream, including several contributions by Metcalfe (see among others Metcalfe (1998)), focuses on the competition/selection side often represented by means of replicator dynamics whereby market shares vary as a function of the relative competitiveness or "fitness" of the different firms.

Finally, many evolutionary models try to unpack the two drivers of evolution distinguishing between some idiosyncratic processes of change in the techniques of production, on the one hand, and the dynamics of differential growth driven either by differential profitabilities and the ensuing rates of investment (such as in R. R. Nelson and Winter (1982)), or by an explicit replicator dynamics, (such in Silverberg et al. (1988) and in Dosi, Marsili, et al. (1995)), on the other.

In the following contribution we shall present a simple multi-firm model, formalizing the mechanisms of learning and selection. It is well placed in the evolutionary tradition but, to our knowledge, well beyond incumbent models, is able to robustly reproduce the foregoing ensemble of empirical stylised facts, including ample heterogeneity in productivity distributions, persistent market turbulence and fat-tailed distribution of growth rates.

One of the basic intuition in our whole interpretation is that both learning and competition processes entail correlation mechanisms which yield as such systematic departures from Gaussian stochastic processes. It is an intuition already explored by Bottazzi and Secchi (2006a) with respect to the exploitation of "business opportunities", which we shall expand also in relation to competition processes. This is what Bottazzi (2014) calls the bosonic nature of firm growth, in analogy with the correlating property of elementary particles - indeed the bosons.

Systematic correlations induce non-fading (possibly amplifying) effects of intrinsic differences, or even different degrees of "luck", across firms, both "intra-period" (however a "period" is defined) and over time.

Bottazzi and Secchi (2006a) show how such correlations generically underlie fat-tailed distributions 
of firm growth rates. We push the analysis further, showing that competition-driven replicators yield similar fat-tailedness properties. Moreover, by unpacking the learning and selection parts of the process, we attempt to distinguish what is generic across all processes and what is specific to particular learning-competition regimes. Finally, our model of industrial dynamics characterised by cumulative learning and competitive selection, or even just the latter (cum entry) is able to account for a few other salient empirical features of industrial change. Section 2 briefly summarizes the empirical regularities and Section 3 discusses the main theoretical models aimed at explaining some of them. Section 4 presents the model and Section 5 analyses the results.

\section{Empirical stylised facts: productivity, size and growth}

During the last few decades, enabled by the availability of longitudinal micro data, an increasing number of studies have identified a rich ensemble of "stylised facts" related to productivities, firm sizes and firm growth rate distributions. Let us consider some of them, germane to the results of the model which follows.

\section{Productivity distribution and growth}

As extensively discussed in Doms and Bartelsman (2000), Syverson (2011), Dosi (2007) and Foster et al. (2008), among many others, productivity dispersion, at all levels of disaggregation, is a striking and very robust phenomenon. Moreover, such heterogeneity across firms is persistent over time, (cf. Bartelsman and Dhrymes (1998), Dosi and Grazzi (2006) and Bottazzi, Secchi, and Tamagni (2008)), with autocorrelation coefficients in the range $0.8-1$. An illustration is provided in Figure 1 for one 2-digit Italian sector and two 3-digit thereof. The distribution and its support are quite stable over time and so is the "pecking order" across firms, as suggested by the high autocorrelation coefficients: see Figure 2. These findings, which hold under parametric and non-parametric analyses, empirically discard any idea of firms' revealed production process as the outcome of an exercise of optimization over a commonly shared production possibility set - which, under common relative prices, ought to yield quite similar input/output combinations. Rather asymmetries are impressive (notice the wide support of the distribution that goes from 1 to 5 in log terms), which tells of a history of both firm-specific learning patterns and of co-existence in the market of low and high productivity firms, with no trace of convergence (see Dosi, Grazzi, Tomasi, et al. (2012)). Even more so, asymmetries are pronounced in emerging economies (with only some reduction along the process of development): see on China, $\mathrm{Yu}$ et al. (2015). In that, the survival of dramatically less efficient firms hint at a structurally imperfect mechanism of market selection, which demand a theoretical interpretation. All this evidence relates to asymmetries in labour productivities but also to firm-level TFPs, notwithstanding the shakiness of the latter notion (more in Dosi, Grazzi, Marengo, et al. (2013), and Yu et al. (2015)).

A less explored phenomenon related to the dynamic of productivity is the double exponential nature of its growth rate distributions. Extensive evidence is provided in Bottazzi, Grazzi, et al. (2005) and Dosi, Grazzi, Tomasi, et al. (2012): see Figure 3 for an illustration. The double exponential nature of growth rate in productivity does not only reveals an underlining multiplicative process that determines efficiency changes, but also suggests processes of idiosyncratic learning characterized by discrete, relatively frequent "big" events.

\section{Size distribution}

Firm size distributions are skewed. And this is an extremely robust property which, again, holds across sectors, countries and levels of aggregation. But, how skewed is "skewed"?

The power-law nature (Pareto or Zipf law, according to the slope of the straight line, in a log-log plot) ${ }^{1}$ of the firm size distribution, has been investigated by many authors ${ }^{2}$ since the pioneering work by $\mathrm{H}$. A. Simon and Bonini (1958). This is not the place to discuss the possible generating mechanism of such distribution (an insightful discussion is in Brock (1999)). Here, just notice that on empirical grounds,

\footnotetext{
${ }^{1}$ See Newman, 2005 for a succinct overview.

${ }^{2}$ See Stanley, Buldyrev, et al., 1995 and Axtell, 2001 for US manufacturing data.
} 


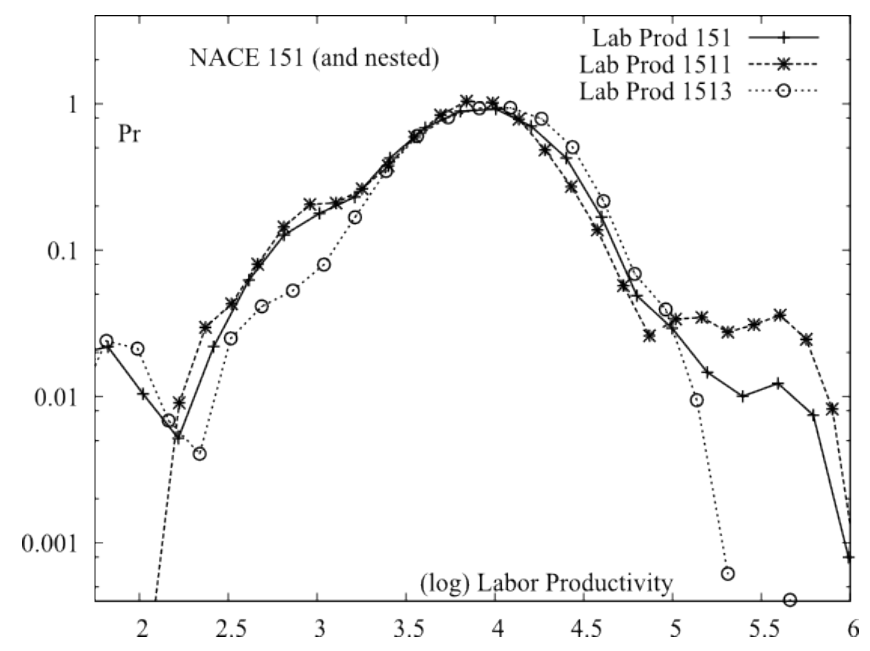

Figure 1: Empirical distribution of labour productivity. Source: Dosi, Grazzi, Marengo, et al. (2013).

\begin{tabular}{lccccc}
\hline \hline \multirow{2}{*}{ SECTOR } & ISIC & \multicolumn{2}{c}{ Labor Prod. } & \multicolumn{2}{c}{$\Pi_{\text {। Growth rates }}$} \\
& Code & AR(1) & Std.Dev. & AR(1) & Std.Dev \\
\hline Production \& processing of meat & 151 & 1.0021 & 0.0016 & -0.3446 & 0.0915 \\
Knitted \& crocheted articles & 177 & 1.0056 & 0.0023 & -0.2877 & 0.1005 \\
Wearing appare \& acc. & 182 & 1.0035 & 0.0012 & -0.3090 & 0.0871 \\
Footware & 193 & 1.0029 & 0.0019 & -0.3903 & 0.0793 \\
Articles of paper and paperboard & 212 & 1.0053 & 0.0008 & -0.3027 & 0.0603 \\
Printing and services related to printing & 222 & 0.9962 & 0.0011 & -0.4753 & 0.1103 \\
Plastic products & 252 & 1.0030 & 0.0010 & -0.3150 & 0.0557 \\
Articles of concrete, plaster \& cement & 266 & 0.9985 & 0.0016 & -0.4572 & 0.0979 \\
Metal products & 281 & 1.0034 & 0.0012 & -0.4125 & 0.0715 \\
Treatment, coating of metal \& mech. engin. & 285 & 1.0051 & 0.0013 & -0.1846 & 0.0679 \\
Special purpose machinery & 295 & 1.0011 & 0.0011 & -0.3040 & 0.0495 \\
Furniture & 361 & 0.9994 & 0.0001 & -0.4472 & 0.0808 \\
\hline \hline
\end{tabular}

Figure 2: AR(1) coefficients for Labour Productivity in levels and first differences, Italy, Istat Micro.1 Dataset. Source: Dosi and Grazzi (2006).

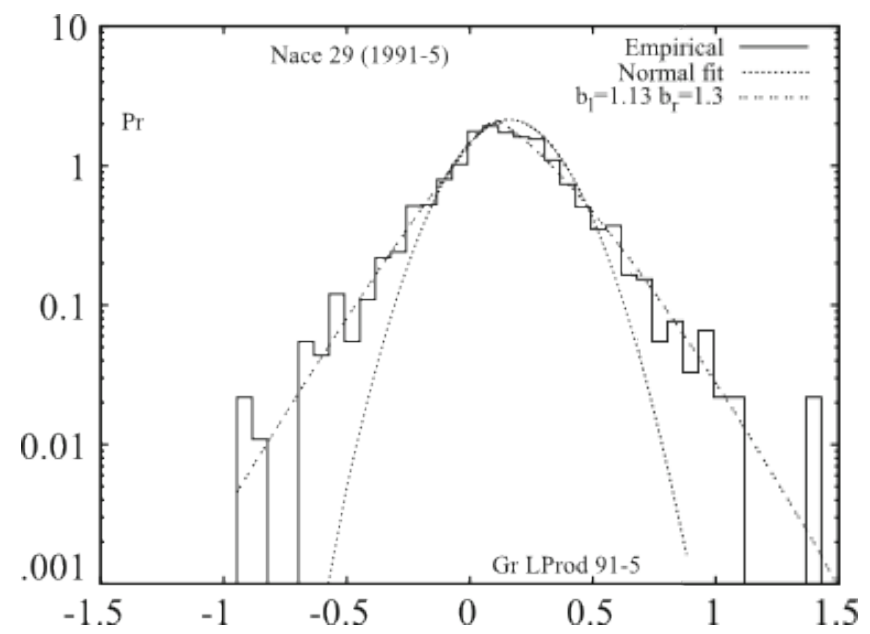

Figure 3: Tent shaped productivity growth rate. Italy, Istat Micro.3 Dataset. Source: Dosi, Grazzi, Tomasi, et al. (2012). 


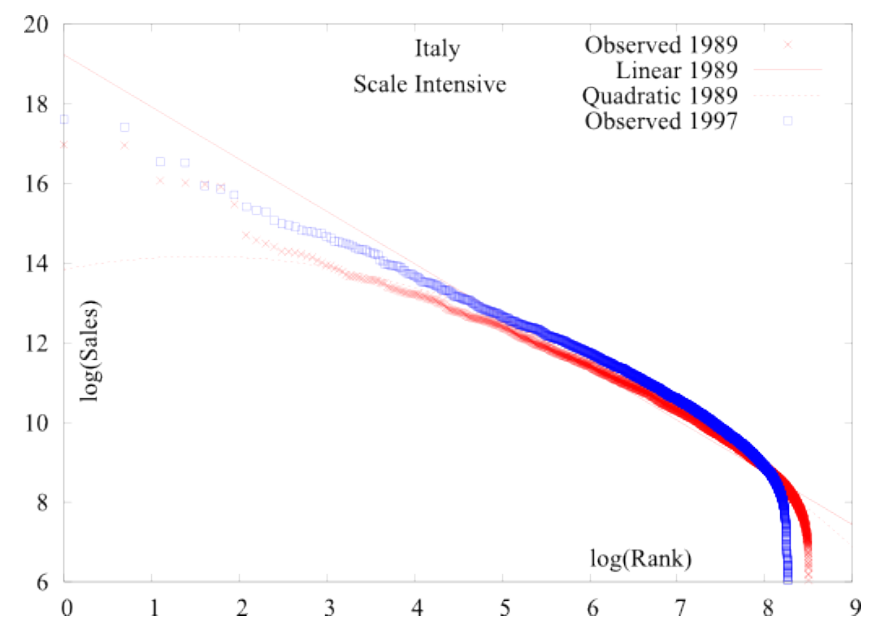

Figure 4: Skewness in the size distribution. Elaboration on Fortune 500. Source: Dosi, Gambardella, et al. (2008).

\begin{tabular}{lcc}
\hline $\mathbf{I}$ & Sales & Value Added \\
\hline mean & 0.130 & 0.161 \\
stdev & 0.048 & 0.045 \\
min & 0.0544 & 0.082 \\
max & 0.559 & 0.601 \\
\hline
\end{tabular}

Table 1: Turbulence Index. Italy, Istat Micro.3 Dataset. Source: Grazzi et al. (2013)

size distributions across manufacturing sub-sectors differ a lot in terms of shape, fatness of the tails and even modality (Bottazzi, Cefis, Dosi, and Secchi (2007) and Dosi, Gambardella, et al. (2008)). Plausibly, technological factors, the different degree of cumulativeness in the process of innovation, the predominance of process vs. product innovation, and the features of market competition might strongly affect (fined defined) sector-specific size distributions (Marsili, 2005). Indeed, it might well be that the findings on the Zipf (Pareto) law distributions are a mere effect of aggregation as already conjectured in Dosi, Marsili, et al. (1995). Hence, what should be retained here is the skewness of the distribution rather than their precise shapes (see Figure 4 for a quite frequent shape of the upper tail).

\section{Market turbulence}

Underneath the foregoing invariances, however, there is a remarkable turbulence involving changes in market shares, entry and exit (cf. the discussion in Baldwin and Rafiquzzaman (1995) and Doms and Bartelsman (2000)). A good deal of such turbulence is due to "churning" of going firms, with $20 \%-40 \%$ of entrants die in the first two years and only $40 \%-50 \%$ survive beyond the seventh year in a given cohort.

An index that synthesizes the market turbulence is shown in Table 1 presenting some synthetic statistics on Italian micro data, both in terms of sales and value added market shares. The $I$ index reads as the sum of the absolute value of market share variations

$$
I=\sum_{i}\left|s_{i}(t)-s_{i}(t-1)\right| \quad 0 \leq I \leq 2
$$

\section{Fat-tailed distributions of growth rates}

A huge empirical literature testifies the emergence of the Laplace distribution in growth rates. A typical empirical finding is illustrated in 5. This applies across different levels of sectoral disaggrega- 


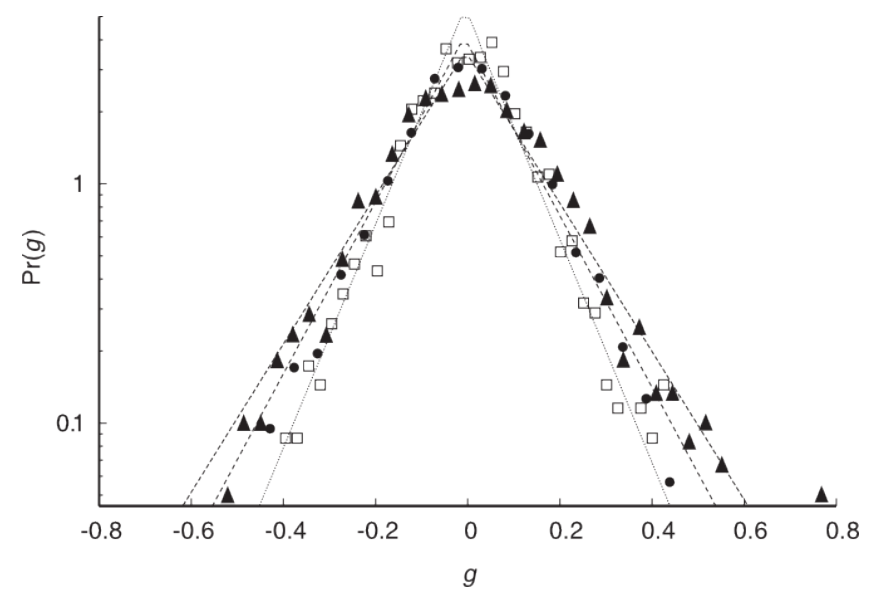

Figure 5: Tent shaped size growth rate, Italy, Istat Micro.1 Dataset. Source: Bottazzi and Secchi (2006a).

tion, across countries, over different historical periods for which there are available data. This stylised fact is robust to different measures of growth, e.g., in terms of sales, value added or employment (for more details see Bottazzi, Cefis, and Dosi (2002), Bottazzi and Secchi (2006a), Bottazzi, Secchi, and Tamagni (2008) and Dosi (2007)).

Firms grow and decline by relatively lumpy jumps which cannot be accounted by the cumulation of small, "atom-less", independent shocks. Rather "big" episodes of expansion and contraction are relatively frequent. More technically, this is revealed by fat-tailed distributions (in log terms) of growth rates. What determines such property?

In general, such fat-tailed distributions are powerful evidence of some underlying correlation mechanism. Intuitively, new plants arrive or disappear in their entirety, and, somewhat similarly, novel technological and competitive opportunities tend to arrive in "packages" of different "sizes" (i.e., economic importance).

\section{Growth-size scaling relationships}

The multiplicative process of firm growth is (roughly) uncorrelated with size, at least for not too small firms. This is what goes under the heading of the Gibrat law.

However, the variance of growth rates falls with size. How the level and growth rate of size are related to each other? Since Stanley, Amaral, et al. (1996), an extensive literature of empirical articles found a negative correlation between the variance of growth rates and size (see Sutton (2002), Lee et al. (1998)). An illustration of the phenomenon is provided in Figure 6. The underlying idea is that firms can be described as a collection of independent units, each of them characterised by an independent growth process. The bigger the firm, the higher the number of its components ("lines of business"). Hence, under an assumption of (quasi) independent growth processes for each unit, the variance of the growth rate decreases proportionally to the inverse square root of size. Bottazzi and Secchi (2006b) convincingly argue that the cause of this negative correlation is product differentiation: bigger firms tend to operate in more sub-markets which are hardly likely to be perfectly correlated. As a direct consequence, the variance of the growth rate ought to fall as the size of firms increases.

To summarize, the challenge for the theory is to account for: [i] persistent heterogeneity in productivities, [ii] skewness in size distributions, [iii] market turbulence, [iv] fat-tailed distribution of growth rates, [v] negative variance-size correlations.

How do incumbent theories fare in this respect? 


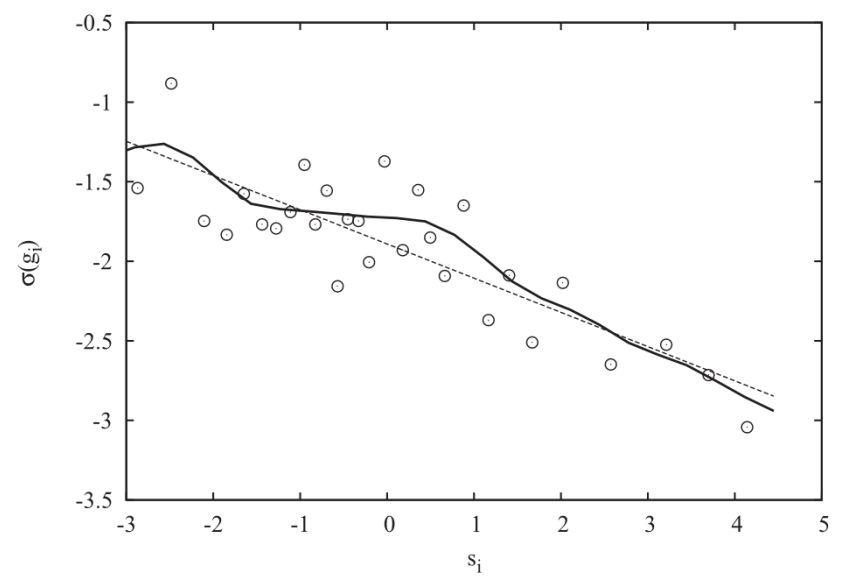

Figure 6: Variance-size relation. Elaboration on PHID, Pharmaceutical Industry Dataset. Source: Bottazzi and Secchi (2006b).

\section{The model}

The model is an evolutionary model microfounded upon simple behavioural rules and heuristics. The absence of any rational expectations (technological or otherwise) is intentionally pursued. Most of individual (and more so organizational) decisions and behaviours take place under conditions of environmental complexity, radical uncertainty and massively imperfect information. The microeconomics of our model fully acknowledges all that and is inscribed within the perspective of "bounded rationality", written large (within a vast literature, see the classic March and H. Simon (1958), R. R. Nelson and Winter (1982), and Gigerenzer and Selten (2002)).

The three processes that take place in the simulated industry are learning, selection and entry-exit.

\section{Idiosyncratic learning processes}

We build upon a simplified version of Dosi, Marsili, et al. (1995) whereby learning is represented by some multiplicative stochastic process upon firms productivities - or more generically "levels of competitiveness" $-a_{i}$ of the form

$$
a_{i}(t)=a_{i}(t-1)\left(1+\theta_{i}(t)\right)
$$

where the $\theta_{i}(t)$ are realizations of a sequence of random variables $\left\{\Theta_{i}\right\}_{i=1}^{N(t)}$, and $N(t)$ is the number of firms. Such dynamics is meant to capture the idiosyncratic accumulation of capabilities within each firm (see Teece et al. (1994) and Dosi, R. Nelson, et al. (2000)). This entails various types of process innovation - yielding higher production efficiency and plausibly lower output prices - and new and improved products. This latter dynamics is not explicitly formalized in our utterly simple model but one may think of new products as higher value added ones, thus implicitly proxied by higher value of $a_{i}$.

The process is a multiplicative random walk with drift: the multiplicative nature is well in tune with the evidence on productivity dynamics under the further assumption that if a firm draws a negative $\theta_{i}$, it will stick to its previous technique (negative shocks in normal times are quite unreasonable!).

We experiment with different learning processes, whereby $\theta_{i}(t)$ is drawn from a set of possible alternative distributions, namely Normal, Lognormal, Poisson, Laplace and Beta. Eq. (2) models learning in our Baseline Regime. Further, we experiment, as one already did in Dosi, Marsili, et al. (1995), with two other more extreme regimes, named Schumpeter Mark I and Schumpeter Mark II, somewhat dramatizing the role attributed to entrants vs. incumbents by the "young Schumpeter" (Schumpeter, 1912) and the "old Schumpeter" (Schumpeter, 1947).

Under Schumpeter Mark I

$$
\theta_{i}(t)=0
$$


for all incumbents. Conversely, under Schumpeter Mark II

$$
\theta_{i}(t)=\pi_{i}(t)\left(\frac{a_{i}(t-1)}{\sum_{i} a_{i}(t-1) s_{i}(t-1)}\right)^{\gamma}
$$

where $\pi_{i}(t)$ is the same draw process as under the Baseline Regime. At one extreme, in the first case, incumbents do not learn after birth. Advances are only carried by new entrants. At the opposite extreme, in the latter case, incumbents do not only learn, but do it in a cumulative way so that a draw by any firm is scaled by its extant relative competitiveness. This captures what Paul David, quoting Robert Merton, called the "Matthew effect". 3

\section{Market selection and birth-death processes}

Competitive interactions are captured by a "quasi replicator dynamics"

$$
\Delta s_{i}(t, t-1)=A s_{i}(t-1)\left(\frac{a_{i}(t)}{\bar{a}(t)}-1\right)
$$

where

$$
\bar{a}(t)=\sum_{i} a_{i}(t) s_{i}(t-1)
$$

where $s_{i}(t)$ is the market share of firm $i$ which changes as a function of the ratio of the firm's productivity (or "competitiveness") to the weighted average of the industry. It is a "quasi-replicator" since a genuine replicator lives on the unit simplex. The "quasi" one may well yield negative shares, under certain parametrizations, in which case the firm is declared dead and market shares are accordingly recomputed. $A$ is an elasticity parameter that captures the intensity of the selection exerted by the market, in terms of market share dynamics and, indirectly, of mortality of low competitiveness firms. Below, we shall study the effect of different degrees of market selectiveness upon industry structures and dynamics.

Finally, we assume that entry of new firms occurs proportionally to the number of incumbents present in the market

$$
E(t)=\omega(t) N(t-1)
$$

where $E(t)$ is the number of entrants at time $t, N(t-1)$ is the number of incumbents in the previous period and $\omega(t)$ is a random variable uniformly distributed on a finite support (which in the following, for simplicity,we assume drawn from a uniform distribution). The idea that the number of entrants is proportional to the number of incumbents is strongly corroborated empirically: see e.g., P. Geroski (1991) and P.A. Geroski (1995). However, the evidence supports also a rough proportionality between entry and exit: thus, in the simplest version of the model, we assume a constant number of firms with the number of dying firms offset by a equal number of entrants.

The productivity of entrants follows a process similar to Eq. (2) but applied to the average productivity of the industry, whose stochastic component $\theta_{j}(t)$ is again a random extraction from alternative distributions (Normal, Lognormal, Poisson, Laplace and Beta)

$$
a_{j}(t)=\left(1+\theta_{j}(t)\right) \sum_{i} a_{i}(t) s_{i}(t-1)
$$

Of course, here $\theta_{j}(t)$ can get negative values. Indeed, the location of the mass of the distribution over negative or positive shocks - captures barriers to learning by the entrant or, conversely, the "advantage of newness".

\footnotetext{
3 "For unto every one that hath shall be given, and he shall have abundance: but from him that hath not shall be taken even that which he hath" (Matthew 25:29, King James Version).
} 


\begin{tabular}{lc}
\hline & Value \\
\hline Number of firms $(N)$ & 150 \\
Initial productivity & 1 \\
Initial market share $(1 / N)$ & 0.006667 \\
$s_{\text {min }}$ & 0.001 \\
$A$ & 1 \\
$\gamma$ & 1 \\
Beta $\left(\beta_{1}, \beta_{2}\right)$ & $(1,5)$ \\
Normal $(\mu, \sigma)$ & $(0.05,0.8)$ \\
Lognormal $\left(\mu_{1}, \sigma_{1}\right)$ & $(-3.5,1)$ \\
Laplace $\left(\alpha_{1}, \alpha_{2}\right)$ & $(0.01,0.015)$ \\
\hline Number of time steps & 200 \\
Number of MC runs & 50 \\
\hline
\end{tabular}

Table 2: Parameters and simulation setup.

\section{Timeline of events}

- There are $N$ initial incumbent firms. At time 0 they have equal productivities and equal market shares.

- At the beginning of each period, except under Mark I Regime, firms learn according to the process specific to each regime.

- Firms acquire or lose market share, according to the replicator.

- Firms exit the market according to the rule: $s_{i}(t)<s_{\text {min }}$.

- The number, the competitiveness and the size of entrants are determined and market shares of incumbents are adjusted accordingly.

\section{Model properties and simulation results}

Let us consider the model properties together with the simulation results which we shall present according to the empirical "stylised facts" the model is able to replicate. The model is parametrized according to Table 2 and the benchmark distribution for the extraction of the micro-shocks is a Beta distribution if not otherwise specified.

\section{Productivity distribution}

The productivity distributions obtained from the three regimes are presented in Figure 7.

The normalized productivity distributions are calculated as

$$
c_{i}(t)=\log a_{i}(t)-\log \sum_{i} a_{i}(t) s_{i}(t-1)
$$

As already mentioned, $c_{i}(t)$ turns out in the real world to be rather disperse over a wide support with a persistency of such asymmetries over time. It is interesting to notice how the support of the distribution (in logs) spans between $(-1,0.5)$ in the Baseline Regime, shrinks in the Mark I Regime $(-0.5,0.2)$, and expands in the Schumpeter Mark II $(-1.4,0.8)$. If innovation is endogenous the support is wider and even more so if it is cumulative as under the Schumpeter Mark II regime.

The autocorrelation structure of productivities is reported in Table 3: the coefficients are well in tune with the empirical evidence. 


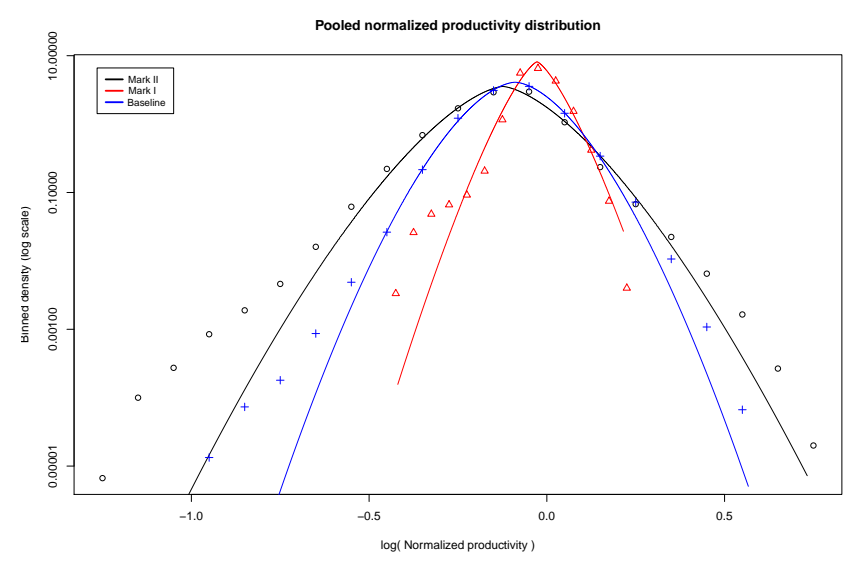

Figure 7: Log normalized productivity distribution across regimes.

\begin{tabular}{lc}
\hline Autocorrelation & $A R(1)$ \\
\hline Baseline Regime & 0.970 \\
Schumpeter Mark I Regime & 0.986 \\
Schumpeter Mark II Regime & 0.987 \\
\hline
\end{tabular}

Table 3: Autocorrelation coefficients in relative productivities.

\section{Market turbulence and concentration}

The dynamic of entry and exit in all scenarios drives an everlasting churning dynamics. Table 4 presents an ensemble of descriptive statistics about the number of entrants, the average age, the average productivity growth, the average size growth, the entry-exit dynamics, and the market concentration. Interestingly, and somewhat counterintuitively, firms' life expectation is the highest under the noincumbent learning (Schumpeter Mark I) regime (21 periods) and the lowest in the cumulative regime (4 periods). This is a robust sign of the effects of "creative destruction" when innovation is endogenous, even (indeed, especially) when learning is highly cumulative, with a galaxy of fringe firms entering and quickly dying around a "core" of successful incumbents. The three regimes show increasing degrees of turbulence, from Mark I to Mark II (see Figure 8). The reported average values are strikingly close to the empirical data shown in Table 1.

Finally, the market concentration, measured by the Herfindahl-Hirschman Index ${ }^{4}$ in typical simulation runs, is illustrated in Figure 9. The Mark I Regime concentration is relatively low and stable over time; conversely, in the Baseline and in the Mark II regimes, phases of high and low concentration alternate, signalling the presence of endogenous cycles which are not related to "market power" but, rather, to the path-dependent dynamics of innovative successes and ensuing differential competitiveness.

\section{Size distribution}

Regarding firm size distribution, proxied by the market shares $s_{i}$, Figure 10 shows the rank-size plot (in logs). If the size distribution follows a power law, being $r_{i}$ the rank of firm $i$, then

$$
s_{i} r_{i}^{\tau}=C
$$

linearising we have

$$
\log r_{i}=\alpha+\tau \log s_{i}
$$

with $\tau$, the slope parameter: under the Zipf law (which is a restriction of the Pareto scaling) $\tau$ is equal to one. Recall from Section 2 above that the empirical size distributions, at relatively disaggregated levels, are far from any power law. And so are generally our results, with a slope clearly different from

\footnotetext{
${ }^{4} H(t)=\sum_{i} s_{i}^{2}(t) \quad 0<H \leq 1$
} 


\begin{tabular}{lcccc}
\hline Baseline Regime & Average & Min & Max & S.E. \\
\hline Number of entrants & 12.14 & 0 & 15.64 & 2.974 \\
& $(0.792)$ & $(0.000)$ & $(1.198)$ & $(0.479)$ \\
Average age & 8.376 & 1 & 11.02 & 1.067 \\
& $(0.286)$ & $(0.000)$ & $(0.383)$ & $(0.171)$ \\
Average productivity growth & 0.046 & 0.045 & 0.051 & 0.001 \\
& $(0.0005)$ & $(0.0004)$ & $(0.0008)$ & $(0.0002)$ \\
Average shares growth & -0.091 & -0.138 & -0.001 & 0.019 \\
& $(0.0065)$ & $(0.000)$ & $(0,0096)$ & $(0,0039)$ \\
Turbulence Index & 0.137 & 0.032 & 0.170 & 0.017 \\
& $(0,006)$ & $(0.0002)$ & $(0.070)$ & $(0,01)$ \\
Herfindahl-Hirschman Index & 0.175 & 0.007 & 0.229 & 0.052 \\
& $(0,014)$ & $(0.000)$ & $(0.0175)$ & $(0.0086)$ \\
\hline Schumpeter Mark I Regime & Average & Min & Max & S.E. \\
\hline Number of entrants & 3.799 & 0 & 13 & 1.334 \\
& $(0.243)$ & $(0.000)$ & $(0.355)$ & $(0.1629)$ \\
Average age & 20.66 & 1 & 24.23 & 4.746 \\
Average productivity growth & $(0.239)$ & $(0.000)$ & $(0.353)$ & $(0.178)$ \\
& 0.002 & 0 & 0.372 & 0.026 \\
Average shares growth & $(0.000)$ & $(0.000)$ & $(0.000)$ & $(0.000)$ \\
Turbulence Index & -0.027 & -0.115 & -0.013 & 0.012 \\
& $(0.0005)$ & $(0.000)$ & $(0.0008)$ & $(0.0004)$ \\
Herfindahl-Hirschman Index & 0.058 & 0.042 & 0.137 & 0.014 \\
& $(0.001)$ & $(0.000)$ & $(0.001)$ & $(0.0007)$ \\
& 0.029 & 0.007 & 0.040 & 0.008 \\
Schumpeter Mark II Regime & $(0.001)$ & $(0.000)$ & $(0.002)$ & $(0.001)$ \\
\hline Average & Min & Max & S.E. \\
Number of entrants & 17.16 & 0 & 22.74 & 4.111 \\
Average age & $(1.249)$ & $(0.000)$ & $(1.849)$ & $(0.750)$ \\
Average productivity growth & 5.306 & 1 & 9.571 & 0.8396 \\
& $(0.2305)$ & $(0.000)$ & $(0.290)$ & $(0.1319)$ \\
Average shares growth & 0.175 & 0.160 & 0.200 & 0.006281 \\
Turbulence Index & $(0.0005)$ & $(0.000)$ & $(0.0007)$ & $(0.002)$ \\
Herfindahl-Hirschman Index & -0.137 & -0.226 & -0.001 & 0.030 \\
& $(0.011)$ & $(0.000)$ & $(0.015)$ & $(0.007)$ \\
& 0.174 & 0.032 & 0.252 & 0.026 \\
& $(0.011)$ & $(0.0002)$ & $(0.017)$ & $(0.007)$ \\
& 0.240 & 0.007 & 0.302 & 0.062 \\
& $(0.014)$ & $(0.000)$ & $(0.002)$ & $(0.001)$ \\
\hline & & & & \\
& & & & \\
& & & & \\
& & & & \\
& & &
\end{tabular}

Table 4: Descriptive Statistics across regimes (50 Monte Carlo runs).

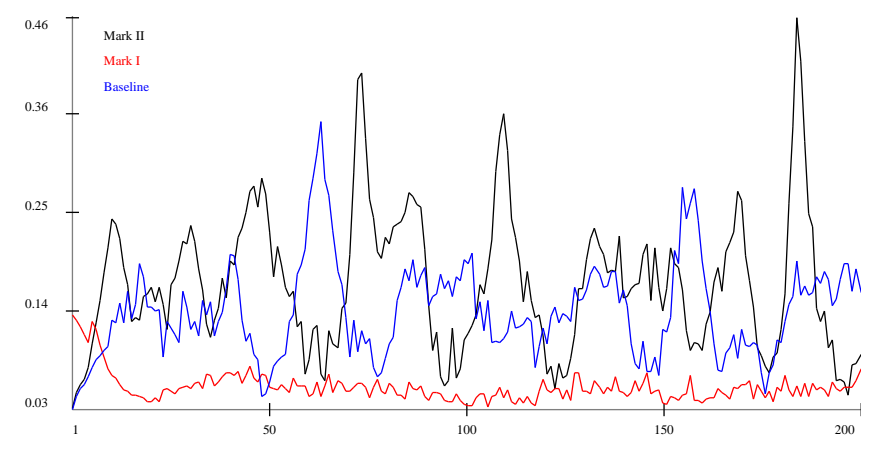

Figure 8: Market turbulence index. 


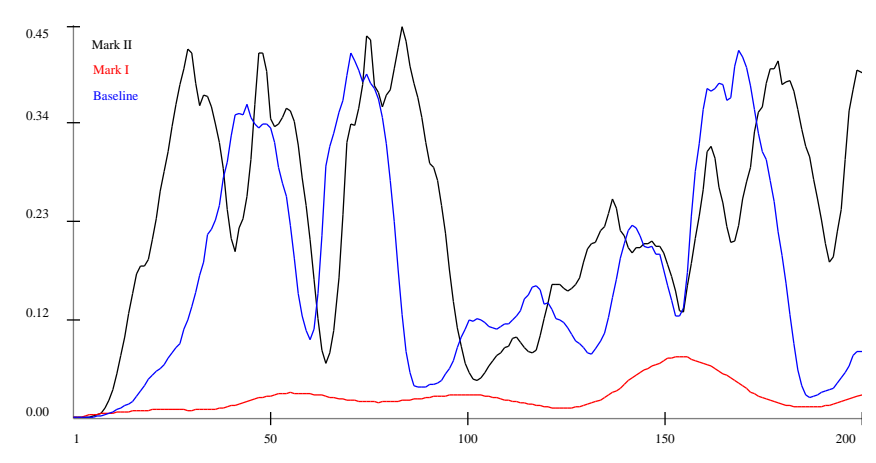

Figure 9: Herfindahl-Hirschman concentration index.

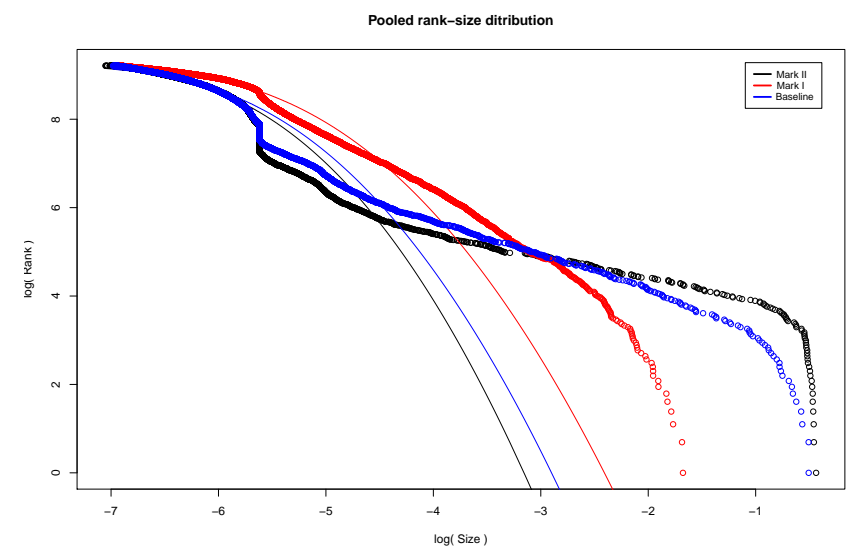

Figure 10: Log rank-size distribution across regimes.

one. However, beyond some cut-off point sizes appear to be rather skewed across all the three regimes (compared with the Lognormal fit which we added as a benchmark). In case of the Schumpeter Mark I, the cut-off point is higher than in the other two cases: a bigger fraction of firms belong to the upper tail in the Baseline and the Mark II regimes. Again, these results seem in line with the empirical evidence discussed in Section 2.2.

\section{Firm growth}

The growth rate of firm sizes is defined as

$$
g_{i}(t)=\log s_{i}(t)-\log s_{i}(t-1)
$$

where market shares are our proxy for size. Figure 11 shows the growth rate distributions across the three regimes. Notice the strong fat-tailed departure from any Normal distribution in all the three regimes.

In order to test for the robustness of these results, we experimented with four alternative distributions for the innovation shocks, namely Laplace, Lognormal, Normal, and Poisson. Figure 12 shows the results for the four distributions across the three regimes. The departure from (log)normality and the emergence of fat tails is rather striking, independently from the shape of the micro-shocks.

To understand how "fat" the tails are, we estimated the parameters of a symmetric Subbotin distribution, defined by the parameters $m, a$ and $b$, wherein $m$ is a location measure, $a$ is the scale parameter capturing the central part of the distribution and $b$ the fatness of the tails. The Subbotin distribution

$$
f_{S}(x)=\frac{1}{2 a b^{1 / b} \Gamma(1 / b+1)} e^{-\frac{1}{b}\left|\frac{x-\mu}{a}\right|^{b}}
$$




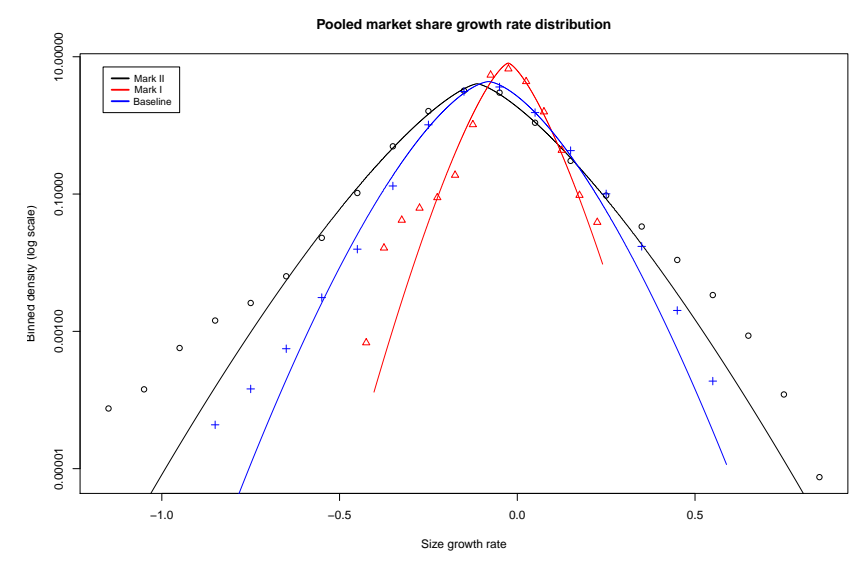

Figure 11: Growth rate distribution across regimes.

according to the value of the parameter $b$, can yield [i] a Normal distribution, if $b=2$, or [ii] a Laplace distribution, if $b=1$. Estimates of the Subbotin distribution parameters are presented in Table 5. Across the three regimes, the value of the $b$ parameter is always significantly smaller than 2 (the Normal case).

What is the source of the tent-shaped distribution of growth rates? Start by noting that the competitive process as such induces ex post correlation in growth rates: the growth of the share of any one firm induces the fall of the total share of its competitors. Indeed, replicator dynamics yields a mechanism of correlation equivalent to a Polya urn mechanism.

As demonstrated by Schreiber (2001) and discussed in Pemantle (2007), the stochastic replicator is a generalized Polya urn scheme. According to the latter, suppose that, at each time $t \geq 0$, there is a population of firms $N(t)$ whose only attribute is the relative "fitness" (or "competitiveness" or productivity as in our case) $m_{i}(t)=a_{i}(t) / \bar{a}(t), i \in\{1, \ldots, N\}$. These firms can be represented in an urn with balls of colors $m$, being $m_{i}(t)$ the relative "fitness" of firm $i$ and the market share $s_{i}(t)$ its outcome. At each time step $t$ two balls (firms) are randomly extracted and get their $m_{i, j}$ compared. The firm with the higher fitness reintroduces its ball and adds another one of the same color. Along the process, being $m_{i}(t)$ a measure of the fitness of firm $i$ in the population, its representation $s_{i}(t)$ (market share) changes proportionally to its fitness against the others $N(t)-1$ firms/balls: the growth of firm $i$ is proportional to its own success against all the other firms, weighted by their own representation in the population. That is, in our formulation

$$
\Delta s_{i}(t, t-1) \simeq a_{i}(t) s_{i}(t-1) / \sum_{i} a_{i}(t) s_{i}(t-1)
$$

As Schreiber (2001) and Pemantle (2007) show, local, pairwise interactions yield asymptotically to the replicator properties of the system. Indeed, the competitive dynamics induces long-range correlations across the whole population also under finite total number of new balls ("opportunities") per period, here as well as in Bottazzi and Secchi (2006a). A tricky issue, in all Polya-type models, is the relationships between the periods over which we measure variables, say years, and the frequency of arrival of "opportunities events". This is beyond the scope of this work. Let us just notice that sufficient to our argument is the monotonicity in the two dynamics.

The basic intuition, our simulations show, holds generically across alternative shapes of micro-shocks and robustly reproduces the fat-tailed distribution of growth rates under the three learning processes. Remarkably, in the Schumpeter Mark II case, a strict Laplace distribution emerges.

\section{Scaling growth-variance relationship}

Figure 13 shows the negative correlation between the variance of growth rate and size, together with an $O L S$ fit for the data

$$
\sigma\left(g_{i}\right)=\alpha+\beta s_{i}
$$




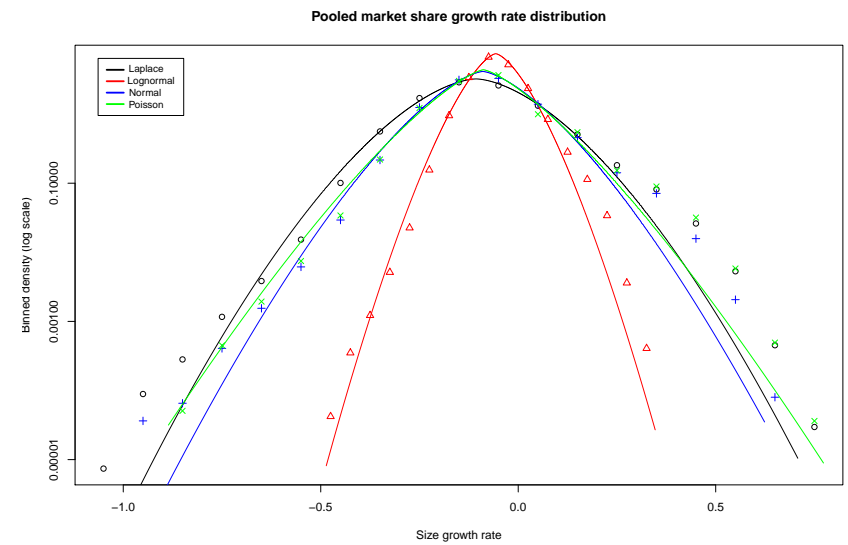

(a) Baseline Regime.

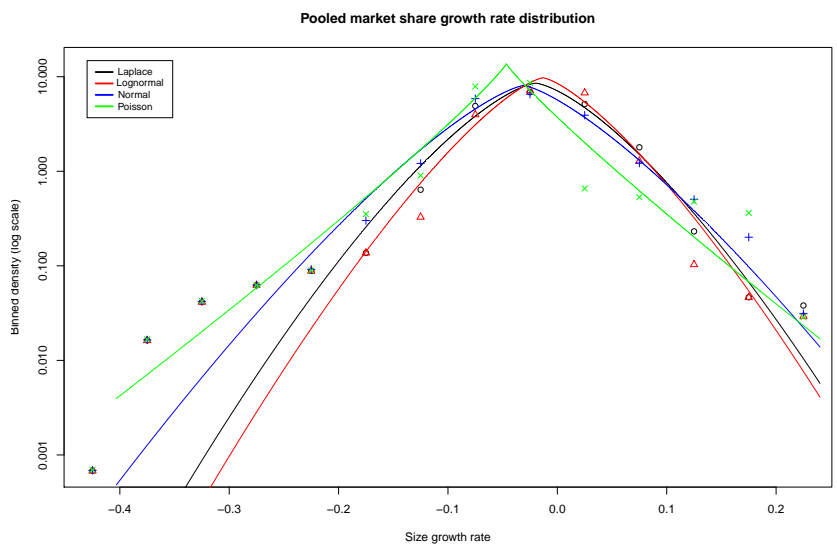

(b) Schumpeter Mark I Regime.

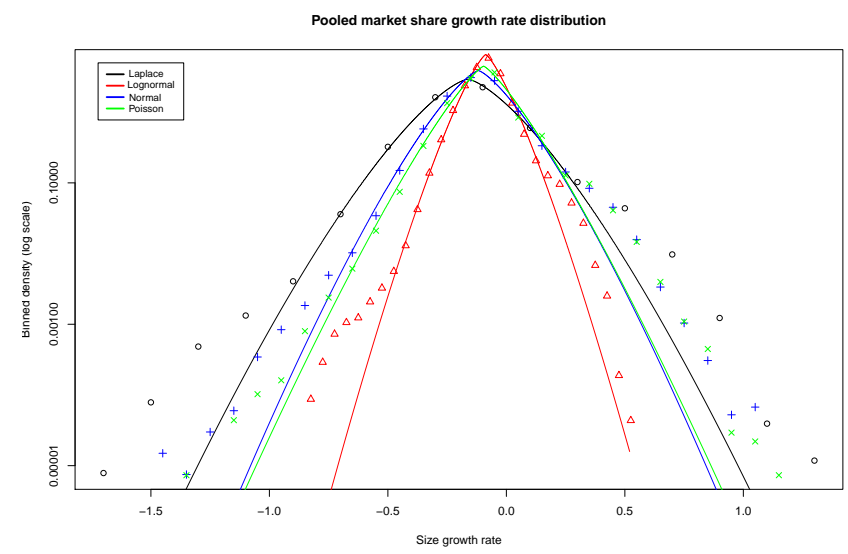

(c) Schumpeter Mark II Regime.

Figure 12: Firm growth rates under different distributions of innovation shocks. 


\begin{tabular}{lccc}
\hline & Baseline Regime & Schumpeter Mark I Regime & Schumpeter Mark II Regime \\
& $b$ & $b$ & $b$ \\
\hline Beta shocks & 1.539 & 1.397 & 1.367 \\
& $(0.006)$ & $(0.003)$ & $(0.006)$ \\
Gaussian shocks & 1.637 & 1.426 & 1.402 \\
& $(0.005)$ & $(0.003)$ & $(0.007)$ \\
Laplace shocks & 1.489 & 1.360 & 1.284 \\
& $(0.007)$ & $(0.003)$ & $(0.007)$ \\
Lognormal shocks & 1.467 & 1.329 & 1.327 \\
& $(0.006)$ & $(0.003)$ & $(0.006)$ \\
Poisson shocks & 1.327 & 0.900 & 1.231 \\
& $(0.007)$ & $(0.001)$ & $(0.007)$ \\
\hline
\end{tabular}

Table 5: Estimation of the $b$ parameters across regimes under different innovation shocks

\begin{tabular}{lc}
\hline Scaling variance-growth & $\beta$ \\
\hline Baseline Regime & -0.2562 \\
& $(0.006)$ \\
Schumpeter Mark I Regime & -0.190 \\
& $(0.01)$ \\
Schumpeter Mark II Regime & -0.4121 \\
& $(0.008)$ \\
\hline
\end{tabular}

Table 6: Estimation of the slope coefficient of linear scaling variance-growth correlation across regimes.

The slope coefficient $\beta$ is presented in Table 6 (here the independent variable are market shares rather than sheer size, but the two, in finite markets, easily map). Across the three regimes, the negative linear correlation is always present. It is important to notice that our scaling is linear in size and not log-linear like in empirical data. However in our simple model we do not have diversification and multi-product firms. And, expectedly, we do not find any power law type scaling of the growth variancesize relationship. But, what is the source of any persistent negative relationship even if of a linear nature? A possible theoretical origin of variance scaling, as already mentioned, has been extensively discussed in Bottazzi and Secchi (2006b), and we believe that is the first order interpretation. In our model there is no possibility of a process of differentiation, but nonetheless the negative scaling holds. Why? Recalling Eq. (5), it is straightforward how the size growth rate depends on the firm relative productivity $m_{i}=a_{i} / \bar{a}$. The higher the size (share) of firm $i$, other things being equal, the nearer the firm is to the market weighted average, since it disproportionally contributes the average itself. It is as if size as such "bends" the selection landscape. In order to visualize this, think of the extreme of a monopolist: in this case, its own competitiveness is also the market average and, of course, the replicator dynamics impact upon growth variance is nil. At the opposite extreme, smaller firms might be by far more or less competitive than the mean but, because of their size, they have a negligible effect upon the "selection" process. Hence, their growth rates are more prone to fluctuate. This induce the emergence of a core-periphery structure where bigger firms tend to have a lower variation in their growth rate while the smaller ones fuel the turbulence of market shares. Needless to say, this interpretation of the variance scaling relation does not contradict the diversification hypothesis. It just adds to it a scale dependence of the very yardstick of competitive selection.

\section{Cumulativeness and selection}

We have argued above that the very competition process robustly induces fat-tailed distributed growth rates, even in absence of learning. But of course, cumulative learning is also plausibly enhancing such fat-tailedness, and so does the increase in the "fierceness" of competition. Let us explore this conjecture 


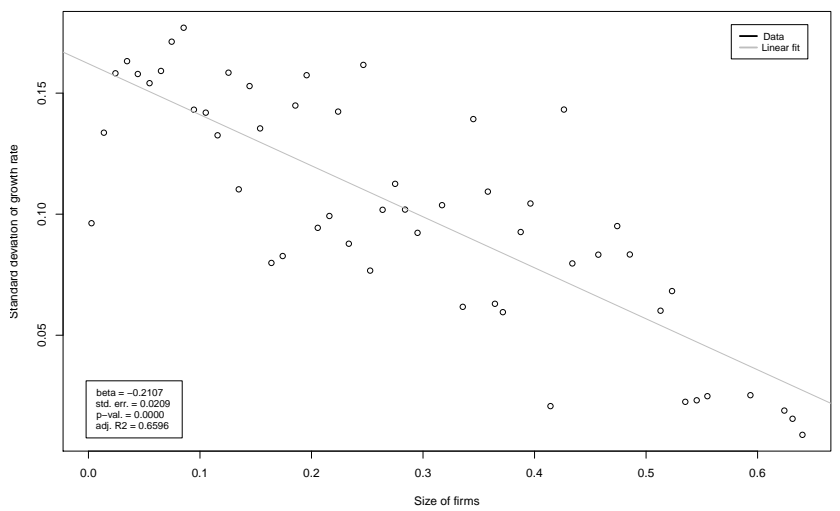

(a) Baseline Regime.

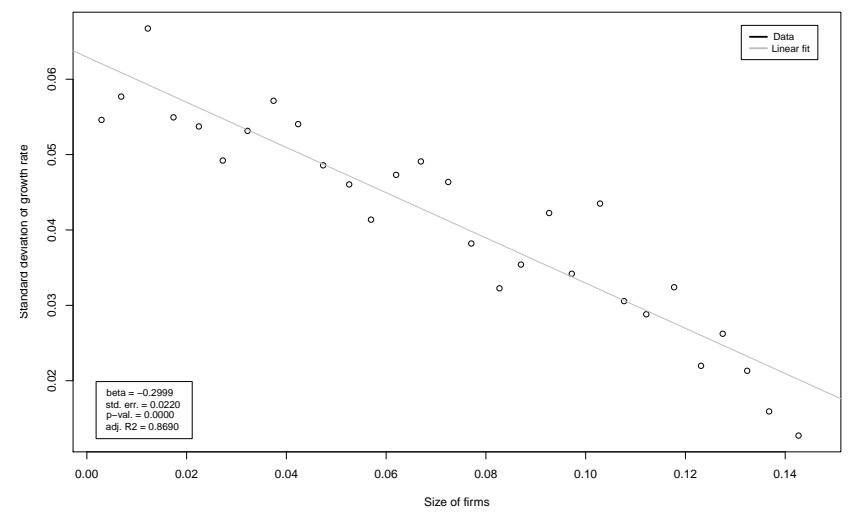

(b) Schumpeter Mark I Regime.

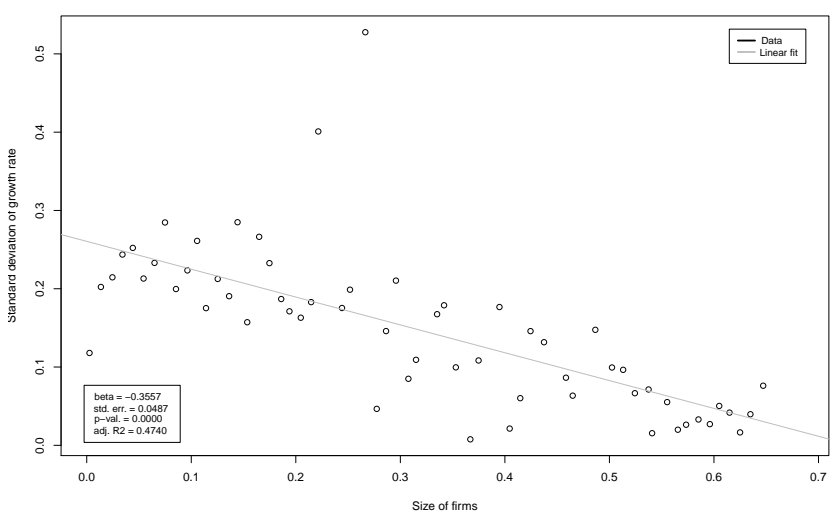

(c) Schumpeter Mark II Regime.

Figure 13: Scaling growth-variance linear relationship across regimes. 


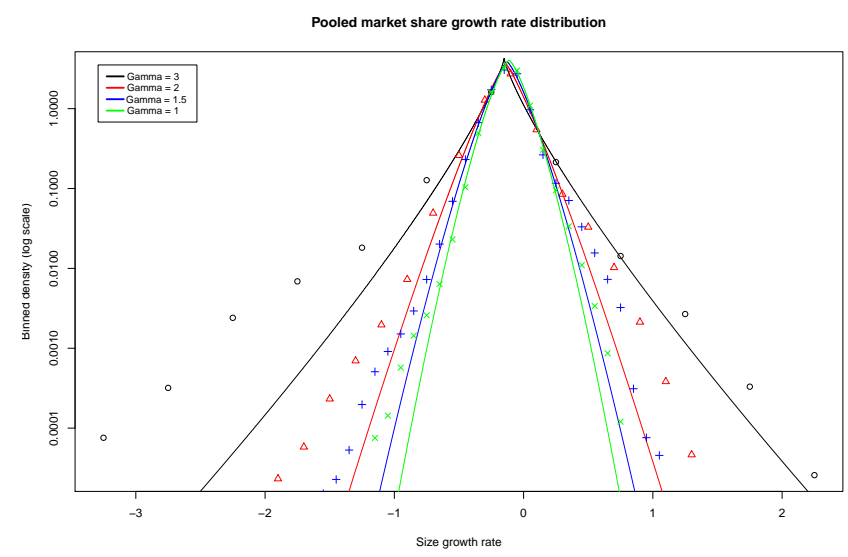

Figure 14: Schumpeter Mark II Regime. Firm growth rate distributions under different degrees of cumulativeness.

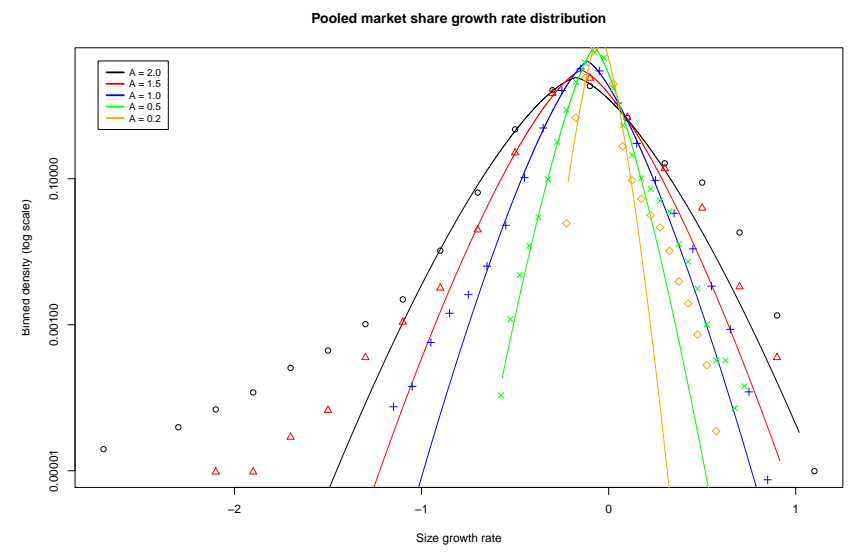

Figure 15: Schumpeter Mark II. Firm growth rates under different selection pressure.

in the case of the Schumpeter Mark II regime. To do this, we study the effects on the distribution of firms growth rate of the $\gamma$ parameter, which captures the degree of cumulativeness in the learning process, and the $A$ parameter, which embodies the selectivity of the market mechanism.

We start by analysing the effect of cumulativeness. As expected, the increase in the $\gamma$ parameter, as shown in Figure 14, induces a more tent-shaped distribution of the growth rates, up to the point of becoming "super Laplacian", with the estimate of $b$ - the tail estimate of the distribution - falling below one. Notice that the estimates under such regime are those which look closer to the empirical ones, circumstantial evidence that Matthews effects are quite widespread. It is worth underlining that the causality here goes from the cumulative learning process to the selection mechanism and, then, to the dynamics of firm growth, in absence of any contemporaneous correlation among the productivity shocks themselves.

Regarding the effect of parameter $A$, Figure 15 illustrates the asymmetric effects of different degrees of market selectiveness. On the one side, $A$ influences the support of the tail of surviving, negative-growth firms and, on the other, the growth of successful ones, that is, the conditions of the coexistence of both high growth firms, the "gazzellas" at the upper-right tail, and the "laggards" at the lower-left tail. This hints that the selection parameter is positively correlated to the asymmetry of the distribution.

\section{Conclusions}

There is an ensemble of "stylised facts" on industrial dynamics which ubiquitously emerges across industries, levels of aggregation, times and countries. They include: wide and persistent asymmetries in degrees of relative efficiency, however measured; skewed size distributions; persistent turbulence in 


\begin{tabular}{lcc}
\hline & Schumpeter Mark II & \\
Cumulativeness & & $b$ \\
\hline$\gamma=1.5$ & & 1.293 \\
& & $(0.008)$ \\
$\gamma=2$ & & 1.176 \\
& & $(0.011)$ \\
$\gamma=3$ & 0.811 \\
& Schumpeter Mark II \\
\hline \multirow{3}{*}{ Selection } & $a$ & $(0.014)$ \\
\hline$A=0.2$ & 0.044 & $b$ \\
\multirow{4}{*}{$A=0.5$} & $(0.002)$ & 1.423 \\
& 0.069 & $1.01)$ \\
$A=1.5$ & $(0.003)$ & $(0.007)$ \\
& 0.1412 & 1.419 \\
$A=2$ & $(0.006)$ & $(0.007)$ \\
& 0.175 & 1.458 \\
& $(0.006)$ & $(0.004)$ \\
\hline
\end{tabular}

Table 7: The effect of cumulativeness and selection pressure.

market dynamics; negative scaling relations between firm sizes and variance in firm growth rates; and, last but not least, fat-tailed distributions of growth rates themselves.

We show that all these regularities can be accounted for by a very simple evolutionary model whereby the dynamics is driven by some learning process by incumbents and entrants (or at least by entrants alone) together with some process of competitive selection. They correlate the growth (and survival) fates across firms, even in absence of correlations in the original "technological shocks" themselves. We also show that this interpretation is robust to different learning and competition regimes, including the extreme archetypes wherein incumbents do not learn at all or, other, with incumbents building success upon success.

\section{References}

Axtell, R. L. (2001). "Zipf Distribution of U.S. Firm Sizes". Science 293.5536, 1818-1820.

Baldwin, J. and M. Rafiquzzaman (1995). "Selection versus evolutionary adaptation: Learning and post-entry performance". International Journal of Industrial Organization 13.4, 501-522.

Bartelsman, E. J. and P. J. Dhrymes (1998). "Productivity Dynamics: U.S. Manufacturing Plants, 1972-1986". Journal of Productivity Analysis 9.1, 5-34.

Bottazzi, G. (2014). "On the Bosonic Nature of Business Opportunities". 15 ISS Conference, Jena, Germany.

Bottazzi, G., E. Cefis, and G. Dosi (2002). "Corporate growth and industrial structures: some evidence from the Italian manufacturing industry". Industrial and Corporate Change 11.4, 705-723.

Bottazzi, G., E. Cefis, G. Dosi, and A. Secchi (2007). "Invariances and diversities in the patterns of industrial evolution: Some evidence from Italian manufacturing industries". Small Business Economics 29.1-2, 137-159.

Bottazzi, G., M. Grazzi, and A. Secchi (2005). "Input output scaling relations in Italian manufacturing firms". Physica A: Statistical Mechanics and its Applications 355.1, 95-102.

Bottazzi, G. and A. Secchi (2006a). "Explaining the distribution of firm growth rates". RAND Journal of Economics, RAND Corporation 37.2, 235-256. 
Bottazzi, G. and A. Secchi (2006b). "Gibrat's law and diversification". Industrial and Corporate Change $15.5,847-875$.

Bottazzi, G., A. Secchi, and F. Tamagni (2008). "Productivity, profitability and financial performance". Industrial and Corporate Change 17.4, 711-751.

Brock, W. (1999). "Scaling in economics: a reader's guide". Industrial and Corporate change 8.3, 409446.

Doms, M. and E. J. Bartelsman (2000). "Understanding Productivity: Lessons from Longitudinal Microdata". Journal of Economic Literature 38.3, 569-594.

Dosi, G. (2007). "Statistical Regularities in the Evolution of industries. A guide trough some evidence and challenges for the theory". In: Perspectives on innovation. Malerba, F. and Brusoni, S. Editors (2007).

Dosi, G., A. Gambardella, M. Grazzi, and L. Orsenigo (2008). "Technological revolutions and the evolution of industrial structures: assessing the impact of new technologies upon the size and boundaries of firms". Capitalism and Society 3.1, 6.

Dosi, G. and M. Grazzi (2006). "Technologies as problem-solving procedures and technologies as inputoutput relations: some perspectives on the theory of production". Industrial and Corporate Change $15.1,173-202$.

Dosi, G., M. Grazzi, L. Marengo, and S. Settepanella (2013). "Production theory: accounting for firm heterogeneity and technical change". 2013/22.

Dosi, G., M. Grazzi, C. Tomasi, and A. Zeli (2012). "Turbulence underneath the big calm? The microevidence behind Italian productivity dynamics". Small Business Economics 39.4, 1043-1067.

Dosi, G., O. Marsili, L. Orsenigo, and R. Salvatore (1995). "Learning, market selection and the evolution of industrial structures". Small Business Economics 7.6, 411-436.

Dosi, G., R. Nelson, and S. Winter (2000). The nature and dynamics of organizational capabilities. Oxford University Press.

Ericson, R. and A. Pakes (1995). "Markov-Perfect Industry Dynamics: A Framework for Empirical Work". Review of Economic Studies 62.1, 53-82.

Foster, L., J. Haltiwanger, and C. Syverson (2008). "Reallocation, Firm Turnover, and Efficiency: Selection on Productivity or Profitability?" American Economic Review 98.1, 394-425.

Geroski, P. (1991). Market dynamic and entry. Wiley-Blackwell.

Geroski, P.A. (1995). "What do we know about entry?" International Journal of Industrial Organization 13.4. The Post-Entry Performance of Firms, 421-440.

Gigerenzer, G. and R. Selten (2002). Bounded rationality: The adaptive toolbox. Mit Press.

Grazzi, M., R. Sanzo, A. Secchi, and A. Zeli (2013). "The building process of a new integrated system of business micro-data 1989-2004". Journal of Economic and Social Measurement 4, 291-324.

Hanusch, H. and A. Pyka (2007). Elgar Companion to Neo-Schumpeterian Economics. Edward Elgar.

Ijiri, Y. and H. Simon (1977). Skew Distributions and the Sizes of Business Firms. North-Holland.

Jovanovic, B. (1982). "Selection and the Evolution of Industry". Econometrica 50.3, 649-70.

Lee, Y. et al. (1998). "Universal features in the growth dynamics of complex organizations". Physical Review Letters 81.15, 3275.

Malerba, F. and S. Brusoni (2007). Perspectives on innovation. Cambridge University Press.

March, J. and H. Simon (1958). Organizations. Wiley.

Marsili, O. (2005). "Technology and the size distribution of firms: evidence from Dutch manufacturing". Review of Industrial Organization 27.4, 303-328.

Metcalfe, J. S. (1998). Evolutionary Economics and Creative Destruction. Routledge. 
Nelson, R. R. and S. G. Winter (1982). An Evolutionary Theory of Economic Change. Cambridge, MA: Belknap Press of Harvard University Press.

Newman, M. (2005). "Power laws, Pareto distributions and Zipf's law". Contemporary physics 46.5, $323-351$.

Pemantle, R. (2007). "A survey of random processes with reinforcement". Probab. Surveys, 1-79.

Schreiber, S. J. (2001). "Urn models, replicator processes, and random genetic drift". SIAM Journal on Applied Mathematics 61.6, 2148-2167.

Schumpeter, J. (1912). Theorie der wirtschaftlichen Entwicklung. Duncker \& Humblot.

Schumpeter, J. (1947). Capitalism, Socialism, and Democracy. New York and London: Harper \& Brothers Publishers.

Silverberg, G., G. Dosi, and L. Orsenigo (1988). "Innovation, Diversity and Diffusion: A Self-organisation Model". Economic Journal 98.393, 1032-54.

Simon, H. A. and C. P. Bonini (1958). "The Size Distribution of Business Firms". The American Economic Review 48.4, 607-617.

Stanley, M., L. Amaral, et al. (1996). "Scaling behaviour in the growth of companies". Nature 379.6568, 804-806.

Stanley, M., S. Buldyrev, et al. (1995). "Zipf plots and the size distribution of firms". Economics letters 49.4, 453-457.

Sutton, J. (2002). "The variance of firm growth rates: the 'scaling' puzzle". Physica A: Statistical Mechanics and its Applications 312.3-4, 577-590.

Syverson, C. (2011). "What Determines Productivity?" Journal of Economic Literature 49.2, 326-65.

Teece, D. J., R. Rumelt, G. Dosi, and S. Winter (1994). "Understanding corporate coherence: Theory and evidence". Journal of Economic Behavior 83 Organization 23.1, 1-30.

Yu, X., G. Dosi, J. Lei, and A. Nuvolari (2015). "Institutional change and productivity growth in China's manufacturing: the microeconomics of knowledge accumulation and "creative restructuring'"'. Industrial and Corporate Change Forthcoming. 